Volume 8 Nomor 2 Tahun 2020

\title{
APPLICATION OF RESOURCE-BASED LEARNING (RBL) MODEL TO IMPROVE NATURAL SCIENCES LEARNING OUTCOMES ON THE THEME OF MY DREAMS TO FOURTH GRADE OF SD NEGERI 2 MEKARSARI IN ACADEMIC YEAR OF 2019/2020
}

\author{
Erika Safira Almas Khaerani ${ }^{1}$, Suhartono ${ }^{2}$, Rokhmaniyah ${ }^{3}$ \\ Sebelas Maret University, Jl. Kepodang 67A Panjer, Kebumen \\ erikasafira99@gmail.com
}

\section{Article History}

accepted 01/06/2020

\begin{abstract}
The aims of the study were: (1) to describe the application of Resource-Based Learning (RBL) model, (2) to improve natural sciences learning outcomes to the theme of my dreams, and (3) to describe the obstacles and solutions to the application of Resource-Based Learning (RBL) model. The research is Collaborative Classroom Action Research (CAR). It was conducted in three cycles. Each cycle consisted of planning, implementing, observing, and reflecting. The types of data were quantitative data and qualitative data. Data collection techniques used observation, interviews and tests. The results of the study indicated that: (1) the steps of RBL model to improve natural sciences learning outcomes to the theme of my dreams involved: a) identifying learning topics, b) arranging how to find information, c) gathering information, d) applying information, e) synthesizing information, and f) doing evaluation; (2) the application of Resource-Based Learning (RBL) model improved natural sciences learning outcomes to the theme of my dreams, (3) the constraints were the students had difficulty in asking questions and expressing their opinions while the solution was the teacher motivated the students to dare in asking questions and expressing opinions.
\end{abstract}

Keywords: Resource-Based Learning (RBL), Learning Outcomes, Natural Sciences

\section{Abstrak}

Tujuan penelitian ini yaitu: (1) mendeskripsikan penerapan model Resource-Based Learning (RBL), (2) meningkatkan hasil belajar IPA tema Cita-citaku, dan (3) mendeskripsikan kendala dan solusi pada penerapan model Resource-Based Learning (RBL). Jenis pendekatan yang digunakan pada penelitian ini yaitu Penelitian Tindakan Kelas (PTK) Kolaboratif. Penelitian ini dilaksanakan dalam tiga siklus. Setiap siklus terdiri dari tahap perencanaan, pelaksanaan, observasi, dan refleksi. Data yang digunakan berupa data kuantitatif dan kualitatif. Teknik pengumpulan data menggunakan observasi, wawancara, dokumen dan tes. Hasil penelitian ini yaitu: (1) penerapan model Resource-Based Learning (RBL) untuk meningkatkan hasil belajar IPA tema Cita-citaku dilaksanakan dengan langkah-langkah: a) mengidentifikasi topik pembelajaran, b) merencanakan cara mencari informasi, c) mengumpulkan informasi, d) menggunakan informasi, e) mensintesis informasi, dan f) evaluasi; (2) penerapan model Resource-Based Learning (RBL) dapat meningkatkan hasil belajar IPA tema Cita-citaku; (3) kendala dalam penelitian ini adalah masih ada peserta didik kurang aktif dalam bertanya dan memberi tanggapan, adapun solusi dari kendala tersebut adalah memberikan motivasi dan pembiasaan kepada siswa agar berani berpendapat dan bertanya.

Kata Kunci: Resource-Based Learning (RBL), Hasil Belajar, IImu Pengetahuan Alam 


\section{PENDAHULUAN}

Kurikulum pendidikan dasar dan menengah menurut Undang-undang Republik Indonesia No. 20 tahun 2003 tentang Sistem Pendidikan Nasional Bab X pasal 37 Ayats1, wajib memuat 10 mata pelajaran, salah satunya adalah IImu Pengetahuan Alam (IPA). Badan Standar Nasional Pendidikan (BSNP, 2006: 161) melalui permendiknas No. 22 tahun 2006 tentang Standar Isi, menyatakan bahwa IImu Pengetahuan Alam (IPA) berhubungan dengan cara mencari tahu tentang alam secara sistematis, sehingga IPA bukan hanya penguasaan kumpulan pengetahuan yang berupa fakta-fakta, konsep-konsep, atau prinsip-prinsip saja tetapi juga merupakan suatu proses penemuan. Pembelajaran IPA di sekolah dasar seharusnya dilaksanakan dengan pembelajaran yang mampu membuat peserta didik berperan aktif menemukan hal-hal yang berkaitan dengan materi pelajaran melalui berbagai sumber belajar. Peran guru dalam pembelajaran yaitu menyediakan, menunjukkan, membimbing dan memotivasi siswa supaya dapat berinteraksi dengan berbagai sumber belajar yang ada. (Komalasari, 2013:111).

Peserta didik sebagai subjek membutuhkan pengembangan diri untuk menggali kemampuan, keterampilan dan bakat yang dimiliki melalui proses pembelajaran. Anak usia 9-11 tahun berada di tahap perkembangan operasional konkret pada masa sekolah dasar. Tahap ini termasuk dalam masa menyelidik dan mencoba yang didorong oleh rasa ingin tahu serta masa anak untuk memusatkan dan menyimpan tenaga guna bereksplorasi. senang berkelompok dan berorganisasi, sungguh-sungguh dalam menyelesaikan tugas, dan perlu petunjuk dari orang tua (Sobur, 2011: 132).

Pembelajaran akan lebih bermakna dan berkesan bagi siswa jika dalam pelaksanaannya melibatkan siswa secara langsung. Hal ini sesuai dengan pembelajaran IImu Pengetahuan Alam (IPA) yang melibatkan percobaan, pengamatan, serta penyimpulan materi. IPA adalah usaha manusia dalam memahami alam semesta melalui pengamatan yang tepat pada sasaran, serta menggunakan prosedur, dan dijelaskan penalaran sehingga mendapatkan suatu kesimpulan (Susanto, 2013 :167).

Berdasarkan hasil observasi yang dilakukan di SD Negeri 2 Mekarsari, dari kegiatan wawancara kepada guru kelas IV diperoleh informasi bahwa aktivitas siswa dalam pembelajaran IPA masih perlu ditingkatkan. Pembelajaran kurang bermakna bagi siswa karena belum melibatkan siswa secara langsung dan memberikan kesempatan bagi siswa untuk menemukan fakta-fakta dan konsep sendiri. Hasil observasi menunjukkan rata-rata hasil belajar siswa belum sesuai harapan dan masih perlu ditingkatkan. Data yang diperoleh dari Penilaian Tengah Semester (PTS) pada kelas IV menunjukkan bahwa terdapat 16 dari 28 siswa yang memperoleh nilai di bawah Kriteria Ketuntasan Minimal (KKM) yang ditentukan oleh sekolah, yaitu 75.

Timbulnya permasalahan pada siswa dalam pembelajaran IPA terjadi karena adanya beberapa faktor diantaranya (1) pembelajaran cenderung masih berpusat pada guru; (2) model yang digunakan belum maksimal dalam melibatkan siswa secara langsung untuk menemukan fakta dan konsep sendiri; dan (3) pemanfaatan sumber belajar yang masih minim. Peran guru dalam pembelajaran adalah menyediakan, menunjukkan, membimbing dan memotivasi siswa agar dapat berinteraksi dengan berbagi sumber belajar yang ada. Bukan hanya sumber belajar yang berupa buku paket maupun orang (guru) itu sendiri, melainkan juga sumber-sumber lain (Komalasari, 2013: 111).

Model Resource-Based Learning (RBL) adalah model pembelajaran konstruktivistik yang memanfaatkan berbagai sumber belajar baik secara individual atau kelompok dengan melibatkan suatu komponen yang dapat memberikan informasi. $\mathrm{Hal}$ ini selaras dengan pendapat Butler (2012: 7) yang menyatakan "Resource-Based learning is one type of constructivist pedagogical theory. Constructivism has, at its base, the assumption that knowledge is not transmitted: it is constructed". Berdasarkan pendapat tersebut, diketahui bahwa Resource-Based Learning (RBL) merupakan salah 
satu model pembelajaran konstruktivistik yang memanfaatkan berbagai sumber belajar karena pada dasarnya pengetahuan bukanlah dipindahkan, melainkan dibangun. Selain itu, Noviana, Susiani, dan Ngatman (2014: 2) menyatakan bahwa ResourceBased Learning (RBL) adalah segala bentuk belajar yang menghadapkan murid dengan satu atau sejumlah sumber belajar secara individual atau kelompok dengan segala kegiatan belajar yang bertalian dengan itu, jadi bukan dengan cara konvensional dimana guru menyampaikan bahan pelajaran kepada siswa. Dalam hal ini guru bukan sebagai satu-satunya sumber belajar. Siswa dapat belajar di dalam kelas, ruang perpustakaan, bahkan di luar kelas dan lingkungan sekolah, saat mempelajari materi tertentu. Model Resource-Based Learning (RBL) mengedepankan interaksi antara siswa dengan sumber belajar. Langkah-langkah yang harus dilakukan dalam pembelajaran berbasis aneka sumber adalah: (a) mengidentifikasi pertanyaan atau permasalahan; (b) merencanakan cara mencari informasi; (c) mengumpulkan informasi; (c) menggunakan informasi; (d) mensintesis informasi; (f) evaluasi. Langkah tersebut sejalan dengan Nasution (2011: 30) yang menyatakan bahwa terdapat 5 hal yang harus diperhatikan dalam pelaksanaan model Resource-Based Learning (RBL) yakni: (1) pengetahuan yang ada, (2) tujuan pembelajaran, (3) pemilihan metode, (4) ketersediaan bahan, dan (5) ketersediaan tempat.

Pelaksanaan model Resource-Based Learning (RBL) pada pembelajaran IPA tema Cita-citaku kelas IV, akan menghadapkan siswa dengan beraneka ragam sumber belajar seperti gambar, video, artikel, perpustakaan, kliping, lingkungan sekolah, dan sebagainya. Melalui model tersebut diharapkan siswa lebih aktif, pembelajaran lebih bermakna dan menyenangkan sehingga hasil belajar IPA meningkat.

Rumusan masalah pada penelitian ini yaitu bagaimana penerapan model Resource-Based Learning (RBL) dalam peningkatan hasil belajar IPA, apakah penerapan model Resource-Based Learning (RBL) dapat meningkatkan hasil belajar IPA, dan apakah kendala dan solusi penggunaan model Resource-Based Learning (RBL) dalam peningkatan hasil belajar IPA kelas IV Negeri 2 Mekarsari tahun ajaran 2019/2020.

Tujuan penelitian ini yaitu untuk mendeskripsikan penerapan model ResourceBased Learning (RBL) dalam peningkatkan hasil belajar IPA, untuk meningkatkan hasil belajar IPA, untuk mendeskripsikan kendala dan solusi penerapan model ResourceBased Learning (RBL) dalam peningkatkan hasil belajar IPA kelas IV Negeri 2 Mekarsari tahun ajaran 2019/2020.

\section{METODE}

Penelitian dilaksanakan di SD Negeri 2 Mekarsari, Kecamatan Kutowinangun, Kabupaten Kebumen. Subjek penelitian ini adalah 28 siswa kelas IV yang terdiri dari 16 siswa laki-laki dan 12 siswa perempuan. Penelitian dilaksanakan dari bulan November tahun 2019 sampai bulan Februari tahun 2020, dengan menerapkan pendekatan penelitian tindakan kelas yang bersifat kolaboratif. Sumber data dalam penelitian ini adalah siswa, guru, dan dokumen. Teknik pengumpulan data berupa observasi, wawancara, dan tes. Uji validitas data menggunakan teknik triangulasi sumber dan triangulasi teknik. Analisis data yang digunakan dalam penelitian ini meliputi analisis kuantitatif dan analis kualitatif. Analisis deskriptif digunakan untuk menganalisis data berupa angka yang disajikan dalam bentuk tabel/grafik. Analisis data secara kualitatif meliputi reduksi data, penyajian data, dan penarikan kesimpulan/verifikasi data.

Indikator keberhasilan penelitian ini adalah pelaksanaan pembelajaran dengan model Resource-Based Learning (RBL) mencapai 85\% dari jumlah ketepatan guru menerapkan model Resource-Based Learning (RBL) serta kesungguhan siswa dalam proses pembelajaran. Hasil belajar setelah menerapkan model Resource-Based Learning (RBL) mencapai target $85 \%$ diukur dari jumlah siswa yang memperoleh nilai $\geq$ 
KKM mata pelajaran IPA yaitu 75 melalui teknik tes. Prosedur penelitian ini dilaksanakan dalam tiga siklus. Tiap siklus terdapat 2 kali pertemuan yang masingmasing terdiri atas perencanaan, pelaksanaan, observasi, dan refleksi.

\section{HASIL DAN PEMBAHASAN}

Penerapan model Resource-Based Learning (RBL) untuk meningkatkan hasil belajar IPA tema Cita-citaku pada kelas IV SD Negeri 2 Mekarsari dilakukan dalam tiga siklus dan tiap siklusnya terdiri dari 2 pertemuan. Proses pembelajaran dilaksanakan dengan langkah: (1) mengidentifikasi topik pembelajaran, (2) merencanakan cara mencari informasi, (3) mengumpulkan informasi, (4) menggunakan informasi, (5) mensintesis informasi, dan 6) evaluasi. Langkah-langkah yang digunakan oleh peneliti mengacu pada langkah-langkah yang dikemukakan oleh Noviana dkk (2014: 2), dan Nasution (2011: 30) yang kemudian disimpulkan menjadi langkah yang disebutkan di atas. Hasil observasi penerapan model Resource-Based Learning (RBL) mengalami peningkatan pada setiap siklusnya hingga mencapai indikator kinerja penelitian yang ditargetkan, yaitu sebesar $85 \%$.

Tabel 1. Persentase Hasil Observasi penerapan model Resource-Based Learning $(\mathrm{RBL})$ terhadap guru dan siswa

\begin{tabular}{lcccccc}
\hline \multirow{2}{*}{\begin{tabular}{l} 
Langkah-langkah \\
\cline { 2 - 7 }
\end{tabular}} & $\begin{array}{c}\text { Guru } \\
(\%)\end{array}$ & $\begin{array}{c}\text { Siswa } \\
(\%)\end{array}$ & $\begin{array}{c}\text { Guru } \\
(\%)\end{array}$ & $\begin{array}{c}\text { Siswa } \\
(\%)\end{array}$ & $\begin{array}{c}\text { Guru } \\
(\%)\end{array}$ & $\begin{array}{c}\text { Siswa } \\
(\%)\end{array}$ \\
\hline $\begin{array}{l}\text { Mengidentifikasi topik, } \\
\text { pertanyaan, atau } \\
\text { permasalahan }\end{array}$ & 72.91 & 79.16 & 89.58 & 91.67 & 97.91 & 100 \\
\hline $\begin{array}{l}\text { Merencanakan cara } \\
\text { mencari informasi }\end{array}$ & 83.33 & 79.16 & 83.33 & 84.72 & 91.67 & 88.89 \\
\hline Mengumpulkan informasi & 77.77 & 62.50 & 84.72 & 87.50 & 94.44 & 90.27 \\
\hline Menggunakan informasi & 63.89 & 76.39 & 81.94 & 84.72 & 90.27 & 87.50 \\
\hline Mensintesis informasi & 71.87 & 73.96 & 87.50 & 87.50 & 93.75 & 90.62 \\
\hline Evaluasi & 80.21 & 73.96 & 85.41 & 79.16 & 89.53 & 89.53 \\
\hline \multicolumn{1}{c}{ Rata- rata } & 74.99 & 74.18 & 85.41 & 85.87 & 92.92 & 91.13 \\
\hline
\end{tabular}

Berdasarkan tabel di atas, diketahui bahwa proses pembelajaran di siklus I, siklus II, dan siklus III selalu mengalami peningkatan. Hasil capaian pendidik dalam mengajar pada siklus I yaitu $74,99 \%$, pada siklus II $85,41 \%$ dan pada siklus III $92,92 \%$ Hasil capaian peserta didik dalam pembelajaran pada siklus I yaitu $74,18 \%$, pada siklus II yaitu $85,87 \%$, dan pada siklus III mencapai $91.13 \%$.

Tabel 2. Analisis Hasil Belajar peserta didik Siklus I, II, dan III

\begin{tabular}{lcccccc}
\hline \multirow{2}{*}{ Keterangan } & \multicolumn{2}{c}{ Siklus I } & \multicolumn{2}{c}{ Siklus II } & \multicolumn{2}{c}{ Siklus II } \\
& Pert. 1 & Pert. 2 & Pert. 1 & Pert. 2 & Pert. 1 & Pert. 2 \\
\hline Nilai Tertinggi & 90 & 100 & 100 & 100 & 100 & 100 \\
\hline Nilai Terrendah & 35 & 55 & 60 & 55 & 60 & 60 \\
\hline Rata-Rata & 73.93 & 79.64 & 81.61 & 82.66 & 87.5 & 88.5 \\
\hline Tuntas & 18 & 19 & 20 & 22 & 25 & 26 \\
\hline Tidak Tuntas & 10 & 9 & 8 & 6 & 3 & 2 \\
\hline
\end{tabular}


Berdasarkan tabel di atas, dapat diketahui bahwa ketuntasan hasil belajar peserta didik selalu mengalami peninggkatan di setiap siklus. Pada siklus I persentase rata-rata siswa yang tuntas yaitu $66,06 \%$, pada siklus II $74.99 \%$, dan pada siklus III $91,06 \%$. Hasil akhir pada siklus III sudah mencapai target yang ditentukan.

Dengan demikian, penerapan model Resource-Based Learning (RBL) dapat meningkatkan hasil belajar IPA tema Cita-citaku. Hal ini karena pembelajaran melibatkan siswa aktif dalam pemanfaatan berbagai sumber belajar. Peningkatan hasil belajar dapat dilihat dari persentase peserta didik yang memenuhi ketercapaian target dari siklus I sampai siklus III. Hasil penelitian ini diperkuat oleh penelitian yang dilakukan oleh Sutriani, Said \& Ratman (2014) yang berjudul "Penerapan Model Resource-Based Learning pada Materi Energi dan Perubahannya untuk Meningkatkan Hasil Belajar Siswa Kelas IV SD Inpres Cendanapura" yang hasilnya menunjukan bahwa persentase skor ketuntasan klasikal siklus I sebesar $65 \%$ dan pada siklus II meningkat dengan persentase skor ketuntasan klasikal sebesar $82 \%$. Hasil belajar dengan pembelajaran yang menerapkan model Resource-Based Learning (RBL) lebih tinggi dibandingkan dengan hasil belajar yang menerapkan model pembelajaran konvensional.

Kendala penerapan model Resource-Based Learning (RBL) untuk meningkatkan hasil belajar IPA tema Cita-citaku di kelas IV SD Negeri 2 Mekarsari tahun ajaran 2019/2020 yaitu (1) siswa tidak berani bertanya dan mengemukakan pendapatnya saat gambar ditayangkan; (2) siswa tidak percaya diri saat membacakan hasil persentasi di depan teman-temannya; (3) saat berdiskusi kelompok suasana kelas kurang kondusif; (4) guru belum fokus dalam menyampaikan materi pembelajaran; (5) siswa terpisah dari kelompoknya dan tidak ikut mengerjakan saat kegiatan di luar kelas; dan (6) siswa tidak menuliskan kesimpulan pembelajaran.

Adanya kendala pada penelitian ini, wajar ditemui karena siswa dan guru belum terbiasa menerapkan model Resource-Based Learning (RBL). Salah satu penyebab kendala ini merupakan kelemahan dari model Resource-Based Learning (RBL) yang dikemukakan oleh Haas (Khaeriyah, 2015: 35) yaitu model ini mengharuskan penyediaan sejumlah sumber belajar dan contoh yang terkadang diluar kemampuan sekolah dan siswa dan Muttaqin (2014: 18) yang mengemukakan bahwa model Resource-Based Learning (RBL) merupakan model yang menuntut persiapan pembelajaran yang matang dari seorang guru.

Adapun solusi dari kendala tersebut yaitu: (1) guru memberikan motivasi dan pembiasaan kepada siswa agar berani berpendapat dan bertanya; (2) guru memberikan dorongan agar siswa selalu percaya diri dalam presentasi; (3) membuat kesepakatan agar semua bekerja dalam kelompok dan guru selalu mengawasi diskusi; (4) peneliti membuat catatan terkait materi agar guru lebih fokus pada ruang lingkup meteri tersebut; (5) memberi arahan agar semua siswa bekerja sama dalam kelompoknya masing-masing dan selalu mengawasi saat kegiatan berlangsung; dan (6) guru menekankan kepada semua siswa agar menulis kesimpulan dan selalu mengawasinya.

\section{SIMPULAN}

Penerapan model Resource-Based Learning (RBL) untuk meningkatkan hasil belajar IPA Tema Cita-citaku pada siswa kelas IV SD Negeri 2 Mekarsari tahun ajaran 2019/2020 dilaksanakan dengan langkah-langkah yaitu: (1) mengidentifikasi topik pembelajaran; (2) merencanakan cara mencari informasi; (3) mengumpulkan informasi; (4) menggunakan informasi; (5) mensisntesis informasi; dan (6) evaluasi. 
Model Resource-Based Learning (RBL) dapat meningkatkan hasil belajar IPA Tema Cita-citaku pada siswa kelas IV SD Negeri 2 Mekarsari tahun ajaran 2019/2020. $\mathrm{Hal}$ ini dibuktikan dengan adanya peningkatan persentase ketuntasan hasil belajar siswa pada setiap siklus penelitian.

Berkaitan dengan hasil penelitian yang telah dicapai, peneliti mengajukan saran sebagai berikut: (1) siswa hendaknya lebih aktif dan fokus saat mengikuti pembelajaran sehingga dapat memahami materi yang disampaikan dan memperoleh hasil belajar yang baik, (2) Penerapan model Resource-Based Learning (RBL) hendaknya dapat dijadikan referensi oleh guru dalam memilih model pembelajaran untuk materi mata pelajaran IPA yang lain atau untuk mata pelajaran yang lain, (3) sebaiknya sekolah dapat melengkapi sarana dan prasarana penunjang proses pembelajaran, sehingga proses kegiatan belajar mengajar dapat berjalan dengan lancar dan bermakna bagi siswa, dan 4) peneliti lain hendaknya dapat meneliti model Resource-Based Learning (RBL) untuk materi mata pelajaran IPA yang lain atau untuk mata pembelajaran lain. 


\section{DAFTAR PUSTAKA}

Badan Standar Nasional Pendidikan. (2006). Standar isi untuk satuan pendidikan dasar dan menengah. Jakarta.

Butler, M. (2012). Resource-based learning and course design: A brief theoretical overview and practical suggestions. Diperoleh 20 November 2019, dari http://papers.ssrn.com/sol3/papers.cfm?abstract_id=1940668.

Khaeriyah, E. (2015). Penerapan model resource based learning (RBL) dengan pendekatan scientific dalam peningkatan pembelajaran IPA tentang sumber daya alam pada siswa kelas IV SDN 1 Klapasawit tahun ajaran 2014/2015. Skripsi. Universitas Sebelas Maret.

Komalasari, K. (2013). Pembelajaran kontekstual konsep dan aplikasi. Bandung: Aditama.

Muttaqin, K. (2014). Pengaruh strategi resource based learning terhadap hasil belajar IPS (sosiologi) siswa di SMP Nusantara Plus kelas VIII. Skripsi. Universitas Islam Negeri Syarief Hidayatullah, Jakarta. Diperoleh 24 Juni 2019, dari http://repository.uinjkt.ac.id.

Nasution. (2011). Berbagai pendekatan dalam proses belajar dan mengajar. Jakarta: Bumi Aksara.

Noviana, L.T, Susiani, T.S, dan Ngatman. (2014). Penggunaan model resource based learning (RBL) dalam peningkatan pembelajaran IPA pada siswa kelas IV SD Negeri 2 Karangsari Tahun Ajaran 2013/2014. PGSD FKIP Universitas Sebelas Maret Surakarta. Diperoleh 2 Juli 2019, dari http://jurnal.fkip.uns.ac.id.

Sobur, A. (2011). Psikologi umum. Bandung: Pustaka Setia.

Susanto, A. (2013). Teori belajar dan pembelajaran di sekolah dasar. Jakarta: Kencana Prenada Group.

Sutriani, E., Said, I., dan Ratman. (2014). Penerapan model resource based learning pada materi energi dan perubahannya untuk meningkatkan hasil belajar siswa kelas IV SD Inpres Cendanapura. Jurnal Kreatif Tadulako Online. 4 (12), 135144. Diperoleh 1 Juli 2019, dari http://www.neliti.com. 